
\title{
$\begin{array}{ll}\text { Research Square } & \begin{array}{l}\text { Preprints are preliminary reports that have not undergone peer review. } \\ \text { They should not be considered conclusive, used to inform clinical practice, } \\ \text { or referenced by the media as validated information. }\end{array}\end{array}$
}

\section{The Association of the BRAF V600E Mutation with Clinicopathologic Characteristics in Chinese Population with Conventional Papillary Thyroid Carcinoma}

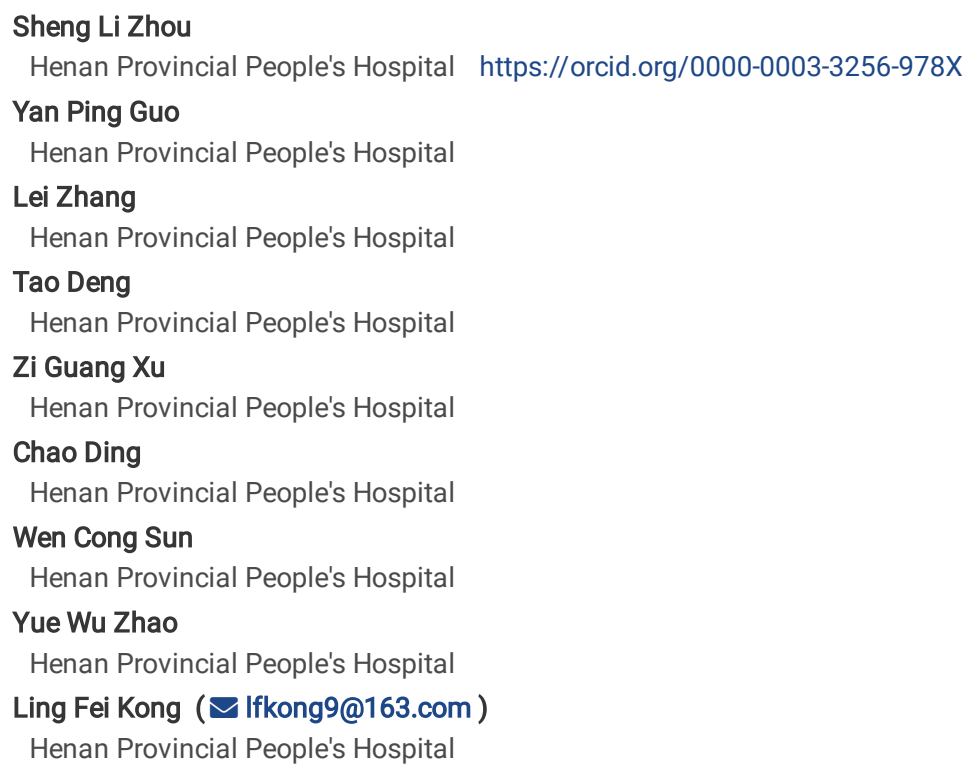

Research

Keywords: Papillary thyroid carcinoma, BRAFV600E mutation, tumor diameter

Posted Date: January 12th, 2021

DOI: https://doi.org/10.21203/rs.3.rs-142136/v1

License: (9) (7) This work is licensed under a Creative Commons Attribution 4.0 International License. Read Full License

Version of Record: A version of this preprint was published at World Journal of Surgical Oncology on July 13th, 2021. See the published version at https://doi.org/10.1186/s12957-021-02326-y. 


\section{Abstract}

Objective:

The aim of the study is to evaluate the association of the BRAFV600E mutation with the clinicopathologic characteristics in Chinese population with papillary thyroid carcinoma (PTC).

Methods

A total of 943 PTC patients who underwent thyroidectomy from 2014 to 2016 at Henan Provincial People's Hospital were included in the present study. The $B R A F^{V 600 E}$ mutation was examined in each resected specimen by quantitative Real-time PCR (qRT-PCR) technique.

Results

The PTC patients were subclassified into the overall, PTC $>10 \mathrm{~mm}$ and papillary thyroid microcarcinoma(PTMC) groups. The positive rate of $B R A F^{V 600 E}$ mutation was $85.4 \%$ in Chinese patients with PTC. In both overall PTC and PTC> $10 \mathrm{~mm}$ groups, the BRAF $F^{\mathrm{V} 600 \mathrm{E}}$ mutation was much more frequently detected in elderly patients and patients at T1 stage $(P<0.05)$. In addition, the positive rate of $B R A F^{V 600 E}$ mutation was significantly higher in PTC patients without concomitant Hashimoto's thyroiditis in overall PTC and PTMC groups $(P<0.05)$. Furthermore, logistic regression analysis suggested that the risk of having a larger tumor diameter was increased by 6-fold when $B R A F^{V 600 E}$ mutation in the PTMC group. No association between the $B R A F^{V 600 E}$ mutation and other clinicopathologic factors was observed.

Conclusion

The $B R A F^{V 600 E}$ mutation was significantly associated with patients age and T stage. Furthermore, the risk of having a larger tumor size was significantly increased when $B R A F^{\mathrm{V} 600 \mathrm{E}}$ mutation in the PTMC group. which suggests that $B R A F^{\mathrm{V} 600 \mathrm{E}}$ mutation might play an important role in the activation of early thyroid carcinogenesis, the effect might weaken in the progression of PTC.

\section{Introduction}

It is important to note that the global incidence of thyroid cancer has been rapidly increasing [1, 2], currently ranking ninth among all cancers. In addition, the global incidence rate of thyroid cancer in women is reported to be three times than that in men [2,3]. Papillary thyroid carcinoma (PTC) is the main subtype of thyroid cancer, which accounts for $85 \%-90 \%$ with an early onset age [2, 3]. Although ultrasonography-guided fine-needle aspiration (US-FNA) biopsy is a standard technique for diagnosing thyroid malignancies measuring $>1-1.5 \mathrm{~cm}, \sim 15 \%-25 \%$ of these malignancies are classified as indeterminate [4], and $\sim 49 \%$ of PTCs measure $\leq 1 \mathrm{~cm}^{2}$, which increases the difficulty in performing US-FNA biopsy. The World Health Organization defines tumors $\leq 1 \mathrm{~cm}$ in diameter as papillary thyroid microcarcinoma (PTMC) [5], which challenges the diagnosis of a US-FNA biopsy. The clinical significance of PTMC remains unclear, although previous reports have indicated that PTMC is related to distant metastasis, mortality, and recurrence [6]; therefore, early PTMC detection and a simultaneous estimation of its clinical significance are essential.

Several genetic biomarkers have been developed to assist in the pathological diagnosis of PTC. Because of its high prevalence and high specificity, $B$-type Raf kinase $(B R A F)^{V 600 E}$ mutation was found to be the most important candidate biomarker for PTC diagnosis. The BRAF ${ }^{V 600 E}$ mutation abnormally activates the mitogen-activated protein kinase pathway and up-regulates cell proliferation and differentiation, eventually resulting in tumorigenesis [7-9]. The global prevalence of the $B R A F^{V 600 E}$ mutation ranges from 33.2\% to $69.7 \%$ [10-23] and is even higher (i.e., from $40.1 \%$ to $75.4 \%$ ) in Chinese patients with PTC [24-30]. While some previous studies have indicated that the $B R A F^{V 600 E}$ mutation might be associated with poor prognostic factors, such as extrathyroidal extension, lymph node metastasis, and advanced tumor stage [10-16, 25-29], other studies have not found any association between the mutation and these factors [17$22,30]$. The association between the $B R A F^{V 600 E}$ mutation and specific clinicopathologic features of PTC remains controversial, and a research focus on the association of the mutation with PTMC has been rare.

In the present study, we aimed to analyze the status of the $B R A F^{V 600 E}$ mutation in 943 patients with PTC and retrospectively examine its possible association with clinicopathologic risk factors.

\section{Patients And Methods}

\section{Patients}

All patients with PTC in the present study who underwent either total thyroidectomy or near-total thyroidectomy in Henan Provincial People's Hospital, China, between October 2014 and October 2016. In total, 943 patients were recruited for this study [men: 233 , mean age(average \pm standard deviation), $52.0 \pm 11.6$ years; women: 710 , mean age, $45.4 \pm 11.6$ years]. All patients received surgical treatment without radioactive iodine ${ }^{131}$ therapy before the surgery. The patients were classified into three groups according to pathologic tumor diameter as follows: the overall PTC group, PTC >10 mm group and PTMC group.

\section{Histopathologic examinations}

Histopathlogic examinations of all patient tissue samples were performed by highly experienced pathologists blinded to $B R A F$ status. Difficult cases were discussed and diagnosed by at least two pathologists. TNM stage was classified based on the 8th edition of the American Joint Committee on Cancer. The majority of patients with PTC (88.8\%; 838/943) were diagnosed as having T1-stage tumors. Lymph node involvement was observed in 377 (54.1\%; 459/848) 
patents. Hashimoto's thyroiditis was confirmed based on the postoperative pathologic findings. The mean follow-up duration was 27 postoperative months (range $=11-44$ months). At the time of follow-up, only two patients died (one patient of breast cancer and another of PTC recurrence).

\section{Analyses of the $B R A F^{V 600 E}$ mutation}

Hematoxylin and eosin-stained slides were reviewed by experienced pathologists. The representative tumor areas were marked to guide microdissection. The tumor areas from 3-4 pieces of 5- $\mu$ m-thick sections of paraffin-embedded tissues were dissected for DNA extraction. The process was performed using the Puregene Tissue Kit (Qiagen, Valencia, CA, USA), according to the manufacturer's instructions. The absorbance of the DNA samples was measured using a spectrophotometer, and only the A260/A280 values between 1.8 and 2.0 were accepted for the next step in the analysis. The extracted DNA was stored at $-80^{\circ} \mathrm{C}$ until use. The status of the $B R A F^{V 600 E}$ mutation in each sample was examined by qRT-PCR using the AmoyDx BRAF ${ }^{V 600 E}$ Mutation Detection Kit (Amoy Diagnostics, Xiamen, China), and the presence of the mutation was evaluated following the manufacturer's instructions. The sample was classified as mutation-positive when the cycle threshold $(C t)$ was $<28$ and as negative when $C t$ was $\geq 28$.

\section{Statistical analyses}

All statistical analyses in present study were analyzed were conducted using SPSS v. 21 (IBM Corporation, Waltham, NY, USA). Discrete variables were presented as number and percentage. Chi-squared or Fisher's exact test was used for categorical variables when comparing frequencies between the groups. All numerical data are expressed as means \pm standard deviations, and differences between the means were compared using Student $t$-test and an analysis of variance for continuous variables. All significant factors by univariate analyses were subjected to logistic regression analysis. A probability value of $<0.05$ was considered statistically significant.

\section{Results}

\section{The frequency of the BRAF ${ }^{V 600 E}$ mutation in patients with PTC}

Of the 943 patients with PTC, there were 570 (60.4\%) PTMC patients and $373(39.6 \%)$ patients with PTC $>10$ mm. The rate of the $B R A F^{V 600 E}$ mutation in all patients with PTC was $85.4 \%$ (806/943) (Table 1). Although the incidence of the $B R A F^{V 600 E}$ mutation in the PTMC group $(86.8 \% ; 495 / 570)$ was higher than that in the PTC >10 mm group $(83.4 \% ; 311 / 373)$, there was no significant difference between the two groups $(P=0.140 ;$ Table 1$)$.

The association between the $B R A F^{V 600 E}$ mutation and clinicopathologic characteristics is detailed in Table 1. The mean age of patients positive of $B R A F^{V 600 E}$ mutation was (46.3 \pm 11.8 ) years, which was elder than patients negative of $B R A F^{V 600 E}$ mutation, logistic regression analyses estimated that advanced age was an independent predictive factor for the $B R A F^{V 600 E}$ mutation $[P=0.03$; odds ration $(\mathrm{OR})=1.02 ; 95 \%$ confidence interval $(\mathrm{Cl})=1.00-1.03](\mathrm{Table} 2)$. Furthermore, the $B R A F^{V 600 E}$ mutation was more likely to be present in patients with T1-stage tumors $[\mathrm{T} 1 \mathrm{vs}$. T2= 86.4\% vs. 83.8\%; $P<0.001 ; \mathrm{OR}(95 \% \mathrm{Cl})=$ 5.78(0.33-0.79); T1: vs. T3 $=86.4 \%$ vs. $60.0 \% ; P=0.005 ; \mathrm{OR}(95 \% \mathrm{Cl})=4.40(1.55-12.45)]$. Moreover, $B R A F^{V 600 E}$ mutation was more frequent in patients without Hashimoto's thyroiditis [concomitant Hashimoto's thyroiditis vs. without concomitant Hashimoto's thyroiditis= 70.0\% vs. $85.5 \% ; P=0.001 ; 0 R(95 \% \mathrm{Cl})=$ $0.37(0.19-0.70)]$. Although the $B R A F^{V 600 E}$ mutation was statistically associated with tumor diameter $(P=0.04)$, logistic regression analysis found no significant difference. No significant differences were found between the status of $B R A F^{V 600 E}$ mutation and the patient's sex, tumor multifocality, lymph node metastasis, or TNM stages.

\section{Clinicopathologic characteristics in the PTC >10mm group}

Similar to that in all patients with PTC, multiple logistic regression analysis suggested that the $B R A F^{V 600 E}$ mutation was more common in elderly patients in the PTC $>10 \mathrm{~mm}$ group[(46.3 \pm 11.7$)$ vs. $(41.0 \pm 13.1) ; P=0.002$, OR $(95 \% \mathrm{Cl})=1.04(1.02-1.06)]$ (Table 2$)$. Furthermore, the $B R A F^{V 600 E}$ mutation was inclined to be positive in T1 stage cancer[T1 vs. T2=85.4\% vs. 83.8\%; $P<0.001 ; \mathrm{OR}(95 \% \mathrm{Cl})=5.91(2.23-15.67) ; \mathrm{T} 1$ vs. T3= $85.4 \%$ vs. $60.0 \% ; P=0.005 ; \mathrm{OR}(95 \% \mathrm{Cl})=4.90(1.63-$ 14.75)]. Although the $B R A F^{V 600 E}$ mutation was statistically associated with a large tumor diameter and more lesions in the $\mathrm{PTC}>10 \mathrm{~mm}$ group $(P<0.05)(\mathrm{Table}$ 1), logistic regression analysis found no significant differences (Table 2). There were also no significant differences in the $B R A F^{V 600 E}$ mutation status among other clinicopathologic characteristics in the PTC >10mm group.

\section{Clinicopathologic characteristics in the PTMC group}

In the PTMC group, $B R A F^{V 600 E}$ mutation-positive patients had a larger tumor diameter than that $B R A F^{V 600 E}$ mutation-negative patients [(6.3 \pm 2.3$)$ vs. (5.1 \pm 2.4) $\mathrm{mm}, P<0.001$ ] (Table 1), logistic regression analysis suggested that the risk of having a larger tumor diameter was increased by 6 -fold when $B R A F^{V 600 E}$ mutation in the PTMC group $(P=0.001 ; \mathrm{OR}=6.26,95 \% \mathrm{Cl}=2.12-20.13)$ (Table 2). Similar to the PTC group patients, the positive rate of $B R A F^{V 600 E}$ mutation in PTMC group patients without Hashimoto's thyroiditis was $87.9 \%$ (470/525), which was significantly higher than that in patients concomitant with Hashimoto's thyroiditis $(71.4 \%, 25 / 35)\left[(P=0.03, \mathrm{OR}(95 \% \mathrm{Cl})=0.41(0.18-0.92)](\right.$ Table 1$)$. No significant differences were found between the $B R A F^{V 600 E}$ mutation status and age, tumor multifocality, lymph node metastasis, or TNM stages.

\section{Discussion}

The present study showed an $85.4 \%$ frequency rate of the $B R A F^{V 600 E}$ mutation in conventional PTC, the proportion was slightly higher in the PTMC group. Previous studies have shown that the $B R A F^{V 600 E}$ mutation is common in PTC patients, the overall prevalence varying from $40.1 \%$ to $76.52 \%$ in Chinese 
patients with PTC [24-30] and from 33.2\% to 70\% in Western countries [11-23]. The possible reasons for the variation in positive mutation rates are PTC subtype, geographic region, ethnicity, and technical differences for $B R A F^{V 600 E}$ examination.

The present study showed that the $B R A F^{V 600 E}$ mutation was much more frequent in elderly patients in both the overall PTC group and PTC $>10$ mm group. Previous studies have also revealed an association between the $B R A F^{V 600 E}$ mutation and elderly patients $[23,27,28]$. The youngest patients in our cohort were 15 years of age. The positive rate of the $B R A F^{V 600 E}$ mutation was $60 \%(3 / 5)$ in patients $<20$ years of age, and it is interesting that this rate increased to more than $80 \%$ in those aged $\geq 20$ years. The possible reason for this phenomenon is that the $B R A F^{V 600 E}$ mutation might occur early in thyroid carcinogenesis, in addition, the effect might become more remarkable along with the development and progress of PTC. However, no such relationship was noted in the results of other studies $[24,25,29]$.

Furthermore, in the present study, the $B R A F^{V 600 E}$ mutation was more likely to be present in patients with a T1-stage tumor than in those with a T2- or T3-stage tumor in both overall and PTC $>10 \mathrm{~mm}$ groups. This phenomenon also indicates that PTC patients having the $B R A F^{V 600 E}$ mutation might be susceptible to an early T stage, and that the mutation might play an important role in the early stages of PTC, but it might also slow PTC progression; however, no significant difference was found among TNM stages, perhaps because all patients enrolled in the present study were in the early stages of the cancer ( 0 and 1$)$. Previous studies have also found no relationship between the $B R A F^{V 600 E}$ mutation and TNM stage [27-30].

Moreover, our data showed that the risk of having a large tumor was increased about 6-fold when $B R A F^{V 600 E}$ mutation in the PTMC group, however, no influence was found in the PTC>10 mm group. This occurrence also indicated that the $B R A F^{V 600 E}$ mutation might be an initiating factor in PTC; however, the probable effect decreased along withing. The reported studies have found no association between the mutation and tumor in PTMC [19,29].

In addition, our results showed that the $B R A F^{V 600 E}$ mutation was more frequent in PTC patients without concomitant Hashimoto's thyroiditis in both overall PTC and PTMC groups. The meta-analysis also suggested that patients negative for the $B R A F^{V 600 E}$ mutation were significantly more likely to have Hashimoto's thyroiditis [22]. Other previous studies found no association between BRAF ${ }^{V 600 E}$ mutation and PTC concomitant Hashimoto's thyroiditis [17-22]. The possible reason of such a discrepancy might be the result of the study population that was different between our study and the above-mentioned study.

There was no relationship between the $B R A F^{V 600 E}$ mutation and both lymph node metastasis and tumor stage in patients with PTC in the present study. Similar phenomena were also reported in previous studies [17-22, 30]; however, several studies have reported that the high-risk clinicopathologic parameters, such as lymph node metastasis and tumor stage, were associated with the $B R A F^{V 600 E}$ mutation [10-16, 25-29]. The inconsistent results might be because of the following factors: geography or ethnicity, sample size, tumor subtypes, or the method used to test the $B R A F^{V 600 E}$ mutation. In addition, $88.5 \%$ of patients with PTC (838/947) enrolled in the present study were at early stages of the disease, limiting the effect of the $B R A F^{V 600 E}$ mutation on progressive clinical characteristics.

The results of our study found no association between the $B R A F^{V 600 E}$ mutation and disease-free survival. Similar results were found in studies on both Korean and Japanese populations [10,13,20]; however, the $B R A F^{V 600 E}$ mutation was reported as an independent prognostic factor in patients with PTC [19, 24]. Numerous reports have indicated that the $B R A F^{V 600 E}$ mutation is associated with disease-free survival even in patients in the early stages of the disease [2528]. The discrepancy among the results of the published studies might be associated with sample size, geographic and ethnic differences, duration of followup, and treatment regimen. Most patients with PTC are diagnosed at early stages of the disease and have a low mortality rate. Majority of the patients enrolled in the present study were at T1 or T2 stage at the time of diagnosis. The intensive initial treatment might be a potential reason for finding no association between the $B R A F^{V 600 E}$ mutation and the disease because patients received all scheduled treatments $[13,30]$.

Strengths of the present study. Firstly, we analyzed the relationship between $B R A F^{\mathrm{V} 600 \mathrm{E}}$ mutation and clinicopathological features in both PTMC and PTC> $10 \mathrm{~mm}$ groups and found that there were different features in each group. Secondly, subjects enrolled in the present study were only conventional PTC to exclude heterogeneity and variations in tumor subtypes. Limitation of our study. Majority of patients enrolled in the present study were at T1or T2 stage when diagnosis and the limited time of follow-up were constrict the effect of clarifying the relationship of $B R A F^{V 600 E}$ mutation and prognosis.

\section{Conclusions}

This study found that an $85.4 \%$ frequency in the $B R A F^{V 600 E}$ mutation in patients with PTC. The BRAF 6000 mutation was associated with elderly patients and early tumor T stages in both overall PTC group and PTC $>10 \mathrm{~mm}$ groupF, BRAF ${ }^{V 600 E}$ mutation was also related to the large tumor diameter in the PTMC group patients. which suggests that $B R A F^{V 600 E}$ mutation might play an important role in the activation of early thyroid carcinogenesis, the effect might weaken in the progression of PTC.

\section{Abbreviations}

PTC: Papillary thyroid carcinoma; US-FNA: Ultrasonography-guided fine-needle aspiration; PTMC: Papillary thyroid microcarcinoma; BRAF: B-type Raf kinase

\section{Declarations}

Authors' Contributions SLZ and LFK conceived of the study, participated in the design of the study and drafted the manuscript. YPG, LZ and YWZ participated in pathological finding analysis. TD and ZGX carried out $B R A F^{V 600 E}$ mutation examination. CD and WCS performed the statistical analysis and clinical data collection. All authors read and approved the final manuscript. 
Funding

This work was supported by The Scientific research project of Science and Technology Department of Henan Province (No. 202102310360).

\section{Availability of data and materials}

The datasets used and/or analyzed during the current study are available from the corresponding author on reasonable request.

\section{Ethics approval and consent to participate}

This study was reviewed and approved by the Declaration of Helsinki and the Institute Research Ethics Committee of Henan Provincial People's Hospital. Written informed consent was obtained from all patients included in the study.

\section{Consent for publication}

Not applicable.

\section{Competing interests}

The authors declare that they have no competing interests.

\section{References}

1. Chen AY, Jemal A, Ward EM. Increasing incidence of differentiated thyroid cancer in the United States, 1988-2005. Cancer. 2009; 115(16):3801-7.

2. Davies L, Welch HG. Increasing incidence of thyroid cancer in the United States, 1973-2002. JAMA. 2006; 295(18):2164-7.

3. Bray F, Ferlay J, Soerjomataram I, Siegel RL, Torre LA, Jemal A. Global cancer statistics 2018: GLOBOCAN estimates of incidence and mortality worldwide for 36 cancers in 185 countries. CA Cancer J Clin. 2018; 68(6):394-424.

4. Alexander EK. Approach to the patient with a cytologically indeterminate thyroid nodule. J Clin Endocrinol Metab. 2008; 93(11):4175-82.

5. Lloyd R, De Lellis R, Heitz P, et al. World Health Organization classification of tumours: pathology and genetics of tumours of the endocrine organs. Lyon, France: IARC Press International Agency for Research on Cancer, 2004; 48-106.

6. Xiang T, Yan W, Zhou L. Retrospective analysis of prognostic factors in patients of papillary thyroid microcarcinoma. Oncotarget. 2018; 9(85):35553-8.

7. Xing M, Westra WH, Tufano RP, Cohen Y, Rosenbaum E, Rhoden KJ, et al. BRAFV600E mutation predicts a poorer clinical prognosis for papillary thyroid cancer. J Clin Endocrinol Metab. 2005; 90(12):6373-9.

8. Xing M. BRAFV600E mutation in papillary thyroid cancer: pathogenic role, molecular bases, and clinical implications. Endocr Rev. 2007; 28(7): 742-62.

9. Tang KT, Lee CH. BRAFV600E mutation in papillary thyroid carcinoma: pathogenic role and clinical implications. J Chin Med Assoc. 2010; 73(3):113-28.

10. Lee JH, Lee ES, Kim YS. Clinicopathologic significance of BRAF V600E mutation in papillary carcinomas of the thyroid: a meta-analysis. Cancer. 2007;110(1):38-46.

11. Elisei R, Viola D, Torregrossa L, Giannini R, Romei C, Ugolini C, et al. The BRAF(V600E) mutation is an independent, poor prognostic factor for the outcome of patients with low-risk intrathyroid papillary thyroid carcinoma: single-institution results from a large cohort study. J Clin Endocrinol Metab. 2012; 97(12):4390-8.

12. Kim SJ, Lee KE, Myong JP, Park JH, Jeon YK, Min HS, et al. BRAF V600E mutation is associated with tumor aggressiveness in papillary thyroid cancer. World J Surg. 2012; 36(2):310-7.

13. Virk RK, Van Dyke AL, Finkelstein A, Prasad A, Gibson J, Hui P, et al. BRAFV600E mutation in papillary thyroid microcarcinoma: a genotype-phenotype correlation. Mod Pathol. 2013; 26(1): 62-70.

14. Gouveia C, Can NT, Bostrom A, Grenert JP, van Zante A, Orloff LA. Lack of association of BRAFV600E mutation with negative prognostic indicators in papillary thyroid carcinoma: the University of California, San Francisco, experience. JAMA Otolaryngol Head Neck Surg. 2013; 139(11):1164-70.

15. Pelizzo MR, Dobrinja C, Casal Ide E, Zane M, Lora O, Toniato A, et al. The role of BRAF(V600E) mutation as poor prognostic factor for the outcome of patients with intrathyroid papillary thyroid carcinoma. Biomed Pharmacother. 2014; 68(4):413-7.

16. Zhang Q, Liu SZ, Zhang Q, Guan YX, Chen QJ, Zhu QY. Meta-Analyses of Association Between BRAF(V600E) Mutation and Clinicopathological Features of Papillary Thyroid Carcinoma. Cell Physiol Biochem. 2016; 38(2):763-76.

17. Fugazzola L, Puxeddu E, Avenia N, Romei C, Cirello V, Cavaliere A, et al. Correlation between B-RAFV600E mutation and clinico-pathologic parameters in papillary thyroid carcinoma: data from a multicentric Italian study and review of the literature. Endocr Relat Cancer. 2006; 13(2):455-64.

18. Ito Y, Yoshida H, Maruo R, Morita S, Takano T, Hirokawa M, et al. BRAFV600E mutation in papillary thyroid carcinoma in a Japanese population: its lack of correlation with high-risk clinicopathological features and disease-free survival of patients. Endocr J. 2009; 56(1):89-97.

19. Choi SY, Park HS, Kang MK, Lee DK, Lee KD, Lee HS, et al. The relationship between the BRAFV600E mutation in papillary thyroid microcarcinoma and clinicopathologic factors. World J Surg Oncol, 2013; 1199: 291-295.

20. Walczyk A, Kowalska A, Kowalik A, Sygut J, Wypiórkiewicz E, Chodurska R, et al. The BRAF(V600E) mutation in papillary thyroid microcarcinoma: does the mutation have an impact on clinical outcome? Clin Endocrinol (Oxf). 2014; 80(6):899-904.

21. Czarniecka A, Kowal M, Rusinek D, Krajewska J, Jarzab M, Stobiecka E, et al. The Risk of Relapse in Papillary Thyroid Cancer (PTC) in the Context of BRAFV600E Mutation Status and Other Prognostic Factors. PLoS One. 2015; 10(7): e0132821. 
22. Niederer-Wüst SM, Jochum W, Förbs D, Brändle M, Bilz S, Clerici T, et al. Impact of clinical risk scores and BRAF V600E mutation status on outcome in papillary thyroid cancer. Surgery. 2015; 157(1):119-25.

23. Kebebew E, Weng J, Bauer J, Ranvier G, Clark O, Duh Q, et al. The prevalence and prognostic value of BRAFV600E mutation in thyroid cancer. Annals of Surgery. 2007; 246(3): 466-471.

24. Zheng X, Wei S, Han Y, Li Y, Yu Y, Yun X, et al. Papillary microcarcinoma of the thyroid: clinical characteristics and BRAF(V600E) mutational status of 977 cases. Ann Surg Oncol. 2013; 20(7):2266-73.

25. Liu S, Zhang B, Zhao Y, Chen P, Ji M, Hou P, et al. Association of BRAFV600E mutation with clinicopathological features of papillary thyroid carcinoma: a study on a Chinese population. Int J Clin Exp Pathol. 2014; 7(10):6922-8.

26. Liu S, Gao A, Zhang B, Zhang Z, Zhao Y, Chen P, et al. Assessment of molecular testing in fine-needle aspiration biopsy samples: an experience in a Chinese population. Exp Mol Pathol. 2014; 97(2):292-7.

27. Shi C, Qin H, Ding C, Sun Y, Lyu Y, Shi T. Association between BRAF V600E mutation and central lymph node metastasis in patients with papillary thyroid carcinoma. Zhonghua Zhong Liu Za Zhi. 2015; 37(2):123-7.

28. Zhang YJ, Liu BG, Zhao ZY, Sheng JD, Feng DD. Relationship and clinical significance between mutated BRAF with prophylactic central-neck nodal dissection in papillary thyroid carcinoma. Beijing Da Xue Xue Bao Yi Xue Bao. 2016; 48(3):502-6.

29. Sun J, Zhang J, Lu J, Gao J, Ren X, Teng L, et al. BRAF V600E and TERT Promoter Mutations in Papillary Thyroid Carcinoma in Chinese Patients. PLoS One. 2016;11(4): e0153319.

30. Shi CL, Guo Y, Lyu YC, Nanding ZABYS, Gao WC, Shi TF, et al. Clinical pathological characteristics of resectable papillary thyroid microcarcinoma. Zhonghua Zhong Liu Za Zhi. 2017; 39(5):361-6.

\section{Tables}

Table 1. Association between the $B R A F^{V 600 E}$ mutation and clinicopathologic characteristics of 943 patients with PTC.

\begin{tabular}{|c|c|c|c|c|c|c|c|c|c|c|c|c|c|c|c|}
\hline \multirow{3}{*}{$\begin{array}{l}\text { Clinico } \\
\text { pathologic } \\
\text { characteristics }\end{array}$} & \multicolumn{6}{|c|}{ Overall PTC $(n=943)$} & \multicolumn{6}{|c|}{ PTC > $10 \mathrm{~mm}(\mathrm{n}=373)$} & \multicolumn{3}{|c|}{ PTMC $(n=570)$} \\
\hline & \multirow{2}{*}{$\begin{array}{l}\text { Total } \\
\mathrm{N}\end{array}$} & \multicolumn{2}{|c|}{ Positive $(n=806)$} & \multicolumn{2}{|c|}{$\begin{array}{l}\text { Negative( } n= \\
137)\end{array}$} & \multirow[t]{2}{*}{$P$} & \multirow[t]{2}{*}{ Total } & \multicolumn{2}{|c|}{$\begin{array}{l}\text { Positive } \\
(\mathrm{n}=311)\end{array}$} & \multicolumn{2}{|c|}{$\begin{array}{l}\text { Negative } \\
(n=62)\end{array}$} & \multirow[t]{2}{*}{$P$} & \multirow{2}{*}{$\begin{array}{l}\text { Total } \\
\mathrm{N}\end{array}$} & \multicolumn{2}{|c|}{$\begin{array}{l}\text { Positive } \\
(\mathrm{n}=495)\end{array}$} \\
\hline & & $\mathrm{n}$ & $(\%)$ & $\mathrm{n}$ & (\%) & & & $\mathrm{N}$ & $(\%)$ & $\mathrm{n}$ & (\%) & & & $\mathrm{n}$ & $(\%)$ \\
\hline \multicolumn{16}{|l|}{ Sex } \\
\hline Male & 233 & 199 & $(85.4)$ & 34 & $(14.6)$ & \multirow[t]{2}{*}{0.974} & 107 & 86 & $(80.4)$ & 21 & $(19.6)$ & \multirow[t]{2}{*}{0.323} & 126 & 113 & $(8 \subseteq$ \\
\hline Female & 710 & 607 & $(85.5)$ & 103 & $(14.5)$ & & 266 & 225 & $(84.6)$ & 41 & $(15.4)$ & & 444 & 382 & $(8 \epsilon$ \\
\hline Age (years) * & 943 & \multicolumn{2}{|c|}{$(46.3 \pm 11.8)$} & \multicolumn{2}{|c|}{$\begin{array}{l}(44.0 \pm \\
11.85)\end{array}$} & 0.03 & 373 & \multicolumn{2}{|c|}{$(46.3 \pm 11.7)$} & \multicolumn{2}{|c|}{$\begin{array}{l}(41.0 \pm \\
13.1)\end{array}$} & 0.001 & 570 & \multicolumn{2}{|c|}{$(46.2 \pm 10$} \\
\hline $\begin{array}{l}\text { Tumor } \\
\text { diameter } \\
(\mathrm{mm})^{*}\end{array}$ & 943 & \multicolumn{2}{|c|}{$(1.13 \pm 0.88)$} & \multicolumn{2}{|c|}{$(1.31 \pm 1.22)$} & 0.04 & 373 & \multicolumn{2}{|c|}{$(1.94 \pm 0.92)$} & \multicolumn{2}{|c|}{$\begin{array}{l}(2.29 \pm \\
1.21)\end{array}$} & 0.04 & 570 & \multicolumn{2}{|c|}{$(0.63 \pm 0.2$} \\
\hline $\begin{array}{l}\text { Lesion } \\
\text { number }\end{array}$ & 943 & \multicolumn{2}{|c|}{$(1.37 \pm 0.69)$} & \multicolumn{2}{|c|}{$(1.26 \pm 0.60)$} & 0.09 & 373 & \multicolumn{2}{|c|}{$(1.45 \pm 0.78)$} & $\begin{array}{l}(1.2 \\
0.56\end{array}$ & & 0.01 & 570 & $(1.32$ & $\pm 0 . \epsilon$ \\
\hline Hashimoto's thy & oiditis & & & & & & & & & & & & & & \\
\hline Yes & 50 & 35 & $(70)$ & 15 & (30) & 0.001 & 15 & 10 & $(66.7)$ & 5 & $(33.3)$ & 0.07 & 35 & 25 & (71 \\
\hline No & 893 & 771 & $(85.5)$ & 122 & $(14.5)$ & & 358 & 301 & $(84.1)$ & 57 & (15.9) & & 525 & 470 & $(87$ \\
\hline Lymph node me & astasis & & & & & & & & & & & & & & \\
\hline Yes & 510 & 443 & (86.9) & 67 & $(13.1)$ & 0.396 & 275 & 229 & (83.3) & 46 & (16.7) & 0.121 & 231 & 211 & (91 \\
\hline No & 433 & 384 & $(88.7)$ & 49 & $(11.3)$ & & 98 & 88 & $(89.8)$ & 10 & $(10.2)$ & & 339 & 299 & $(8 \varepsilon$ \\
\hline T staging & & & & & & & & & & & & & & & \\
\hline T1 & 838 & 724 & $(86.4)$ & 114 & $(13.6)$ & 0.001 & 268 & 229 & $(85.4)$ & 39 & $(14.6)$ & 0.005 & 570 & 495 & $(86$ \\
\hline T2 & 80 & 67 & $(83.8)$ & 13 & $(16.3)$ & & 80 & 67 & $(83.8)$ & 13 & $(16.3)$ & & -- & -- & -- \\
\hline T3 & 25 & 15 & $(60.0)$ & 10 & $(40.0)$ & & 25 & 15 & $(60.0)$ & 10 & $(40.0)$ & & -- & -- & -- \\
\hline Tumor staging & & & & & & & & & & & & & & & \\
\hline 0 & 856 & 728 & $(85.0)$ & 128 & $(15.0)$ & 0.245 & 320 & 262 & $(81.9)$ & 58 & (18.1) & 0.055 & 536 & 466 & $(86$ \\
\hline 1 & 87 & 78 & (89.7) & 9 & $(10.3)$ & & 53 & 49 & $(92.5)$ & 4 & (7.5) & & 34 & 29 & (85 \\
\hline
\end{tabular}

Abbreviations: PTMC, papillary thyroid microcarcinoma; PTC, papillary thyroid carcinoma; LNM, lymph node metastasis. 
*Numbers are presented as mean \pm standard deviation.

Table 2. Multivariate analysis of the association of the $B R A F^{V 600 E}$ mutation with clinicopathologic characteristics in papillary thyroid carcinoma patients.

\begin{tabular}{|c|c|c|c|c|c|c|}
\hline & \multicolumn{2}{|l|}{ Overall } & \multicolumn{2}{|c|}{ PTC $>10 \mathrm{~mm}$} & \multicolumn{2}{|l|}{ PTMC } \\
\hline & $P$ & OR $(95 \% \mathrm{Cl})$ & $P$ & OR $(95 \% \mathrm{Cl})$ & $P$ & OR $(95 \% \mathrm{Cl})$ \\
\hline Age (years) & 0.03 & $1.02(1.00-1.03)$ & 0.002 & $1.04(1.02-1.06)$ & 0.805 & -- \\
\hline Tumor diameter (mm) & 0.417 & -- & 0.756 & -- & 0.001 & $6.53(2.12-20.13)$ \\
\hline Hashimoto's thyroiditis & 0.001 & $0.35(0.18-0.67)$ & 0.07 & -- & 0.03 & $0.41(0.18-0.92)$ \\
\hline \multicolumn{7}{|l|}{ T stage } \\
\hline \multicolumn{7}{|l|}{ T1 } \\
\hline $\mathrm{T} 2$ & $<0.001$ & $5.78(2.43-13.80)$ & $<0.001$ & $5.91(2.23-15.67)$ & -- & -- \\
\hline T3 & 0.005 & $4.40(1.55-12.45)$ & 0.005 & $4.90(1.63-14.75)$ & -- & -- \\
\hline
\end{tabular}

Notes: OR $(95 \% \mathrm{Cl})=$ Odds ratio $(95 \%$ confidence interval). 